\title{
VIAGENS E NARRATIVAS (AUTO)BIOGRÁFICAS
}

\section{Apresentação}

Quem nunca se imaginou atravessando terras, céus e mares em busca do desconhecido, do inusitado, do novo? Uma propaganda e até mesmo uma revista que se vê de relance em uma banca de jornais despertam o desejo de partir, sumir, mudar, experimentar. Apesar de sempre ter existido a curiosidade pelo estranho e o exótico, o educador Francisco Venâncio Filho (1941)', considerava que, o gosto pela viagem era moderno na medida em que se tornara possível viajar pelo livro, pela revista ilustrada ou pelo cinema. No seu entendimento, elas podiam ser de diferentes gêneros e espécies: de negócio, de saúde, de luxo, de recreio e de cultura, exigindo sempre um cuidado especial. Assinalava, ainda, existir, uma "encantadora psicologia da viagem" (idem, p. 119), como sugeria Paul Morand, em Le voyages (notes $e$ maximes), o que envolvia um projeto com previsão de custos e itinerários, o que seria precedido da reunião de mapas, guias, prospectos e conhecimento de uma literatura especializada, capazes de fornecer informações preciosas e precisas. No delineamento de uma certa pedagogia da viagem, Venâncio Filho, sinaliza para a importância de estudo e planejamento, como a necessidade de viajar com pouca bagagem, comprar o menos possivel e conhecer pelo menos cem palavras do país visitado para ter acesso a números, moedas, passagens e alimentação. Alertava ainda: “A preparação cultural da viagem torna-se condição para que se aproveite o mais possivel" (idem, p. 123).

Quem nunca tomou uma xícara de café ou saboreou um chocolate quente, numa cafe-

1 VENÂNCIO FILHO, Francisco. A educação e seu aparelhamento moderno. Rio de Janeiro: Companhia Editora Nacional. Coleção Atualidades Pedagógicas, Biblioteca Pedagógica Brasileira, v. 38, 1941. teria, com papel e caneta nas mãos, enquanto descansa de caminhadas, para contar das descobertas, dos encontros, das surpresas e das decepções com a viagem? Quem nunca saiu do caminho, em busca de uma estação de correios, para, com o coração aos sobressaltos, fechar um envelope repleto de carimbos e belos selos, para enviar notícias? Quem nunca se viu com um cartão postal nas mãos, com a melhor vista ou monumento de uma cidade, cuidadosamente selecionado, para encurtar distâncias, amenizar saudades ou aguçar a curiosidade do amigo, do familiar ou do amado, convidando-o, assim, a compartilhar a viagem? Nelson Schapochnik (1998)², lembra que

Uma vez atingido o seu destino postal, a viagem recomeça. Mas, agora, o viajante é aquele que recebeu o cartão. Viagem virtual por outros mundos, com o recurso dos fragmentos de imagens postais e de imaginação. Seria como se the fosse dada a oportunidade de compartilhar as vacilações da significação, a magia das perspectivas ou ainda as glórias da conquista de um novo espaço. 0 realismo das imagens estampadas nos postais também cria uma disposição que transfere o sentido de 'eu li' para 'eu vi'. A posse do cartão daria ao destinatário a chance de sentir-se como Ulisses, Marco Polo ou Pero Vaz de Caminha. (p. 424)

Quem nunca se viu rodeado de amigos, contando de passeios, sabores e cheiros da cidade que acaba de conhecer? Quem nunca organizou álbuns de fotografias de um país distante? Quem nunca mostrou inúmeras imagens de museus, paisagens, pessoas encontradas du-

2 SCHAPOCHNIK, Nelson. "Cartões-postais, álbuns de família e icones da intimidade". In: NOVAIS, Fernando (Coord. coleção) e SEVCENKO. Nicolau (Coord. do volume). História da vida privada no Brasil. São Paulo: Companhia das Letras, 1998, v. 3. p. 423-512. 
rante a travessia? Quem nunca teve que escrever relatórios ou fazer palestras, consultando anotações, bilhetes, passagens, que comprovem o visto e o vivido? Marta Chagas de Carvalho $(2007)^{3}$ assinala que tão importante quanto viajar é dar visibilidade à mesma. Viagens educam. Viagens legitimam. Viagens abrem caminhos. Viagens se desdobram em outras viagens, em redes de afetos, em projetos e realizações.

Certamente, as perguntas podem até sugerir que as possibilidades de viajar são dadas indiscriminadamente a todos, mas, uma rápida passagem de olhos por uma das mais alentadas obras sobre o tema - Viajeras entre dos mundos -, imediatamente traz à tona a certeza de que as viagens nem sempre foram permitidas às mulheres e, quando o foram, nem sempre elas puderam dar visibilidade às mesmas. Sara Beatriz Guardia (2012) ${ }^{4}$, no prólogo do livro que se volta para discursos de viagens e viajantes, viagens e discurso testemunhal, viajantes e escritura: a pena feminina, construção de uma cultura de viagem feminina na ficção, observa que

Desde el comienzo de la escritura de la historia y aún cuando la transmisión oral registraba los hitos y las creencias fundamentales, los viajes fueram território masculino, unido a la aventura, la audácia y el valor; mientras que las mujeres se mantuvieram confinadas al hogar y a la vida sedentaria. Sin embargo, algunas se aventurarron más allá de las fronteras permitidas, traspasaron limites y espacios impuestos, tuvieon la osadia de enfrentar y superar desafios y peligros, asumiendo com pasion sus propias conviccones, lo que les deparo el destino, ó simplesmente el viaje que debieron realizar por causas externas a su propia voluntad. ${ }^{5}$ (GUARDIA, op. cit. p. 9)

3 CARVALHO, Marta Chagas de. "A bordo do navio, lendo notícias do Brasil: o relato de viagem de Adolphe Ferrière" In. MIGNOT, Ana Chrystina; GONDRA, José (orgs). Viagens Pedagógicas. São Paulo: Cortez Editora, 2007. p. 277-293.

4 GUARDIA, Sara Beatriz (editora). Viajeras entre dos mundos. Dourados: Ed. UFGD, 2012.

5 Desde o começo da escrita da história e ainda quando a transmissão oral registrava os mitos e as crenças fundamentais, a viagens foram território masculino, unido à aventura, à audácia e ao valor, enquanto as
Assim como relatos de mulheres, pouco encontramos do testemunho de crianças que seguiram familiares, sem possibilidade de escolher entre permanecer ou prosseguir. Afinal, nem sempre as viagens se deram por vontade própria, curiosidade ou necessidade do viajante, como poderíamos supor quando imaginamos as delícias de atravessar o mundo em busca do inusitado. Escravizados, exilados, degredados, refugiados, partiram a contragosto, por imposição, intolerância, ou para fugir da guerra, da violência, do frio, da sede, da fome. Alguns deixaram registros escritos. Outros, legaram histórias que nos são narradas oralmente por várias gerações por aqueles e aquelas que guardam memórias familiares de arbítrios, sofrimentos, desesperanças.

Dentre as recentes publicações voltadas para escritas infantis e, particularmente, as viagens de crianças ou, melhor dizendo, as escritas de viagem de crianças, destaca-se: Palabras huérfanas: los niños y la Guerra Civil, de Verônica Sierra Blás (2009)6 que explora as cartas escritas por crianças espanholas durante o período de exílio na União Soviética, de onde escreveram para seus pais, familiares, amigos e órgãos de assistência. Ao se voltar para as cartas escritas pelas crianças, a autora acredita que estaria dando a conhecer uma versão desta história, diferente daquela que ao privilegiar crônicas jornalísticas e documentos oficiais da época, tem desprezado preciosos testemunhos daqueles que viveram uma experiência que modificou seus destinos, deixando-os órfãos "ainda que muitos não o fossem de verdade" (p. 21). Por isso, Verónica

mulheres eram mantidas confinadas à casa e à vida sedentária. Sem dúvida, algumas se aventuraram para além das fronteiras permitidas, ultrapassaram limites e espaços impostos, tiveram a ousadia de enfrentar e superar desafios e perigos, assumindo com paixão suas próprias convicções, o que thes preparou o destino, ou simplesmente a viagem que realizaram por causas externas à sua própria vontade.

6 SIERRA BLÁS, Verónica. Palabras huérfanas: los niños y la Guerra Civil, Madrid: Taurus, 2009. 
está presente neste dossiê, com Las cartas de los "niños de Rusia": diarios de a bordo de un exilio sin retorno, no qual a escrita de crianças, exílio e guerra civil se entrecruzam para dar a conhecer uma versão muito diferente da consagrada na historiografia, uma versão que traduz sofrimento, solidão, saudades, pois escrever nestas circunstâncias, no seu entendimento, significou um exercício terapêutico que propiciava aliviar tensões, liberar sentimentos íntimos, resistir à humilhação e opressão, combater os medos, enquanto desabafavam sobre o que os afligia.

Pelo texto Viagens $e$ passeios familiares $e$ escolares registrados em cadernos de alunos (1957-2015), Eliane Peres mergulha em registros de viagens e de passeios realizados por crianças, em cadernos escolares de alunos do Ensino Fundamental que estão sob a guarda do grupo de pesquisa História da Alfabetização, Leitura, Escrita e dos Livros Escolares (HISALES), da Faculdade de Educação da Universidade Federal de Pelotas (RS). Neste exercício de interpretar deslocamentos sob a supervisão da família ou da escola, convida a pensar que a escola, onde se aprende a escrever sobre si mesmas, as crianças são levadas a registrar suas experiências durante as férias, mas também a experimentar a viagem e os passeios como pretextos para trabalhar conteúdos curriculares. A autora ainda alerta quando se debruça sobre cada texto: trata-se de "uma experiência vivida? Desejada? Inventada? Copiada?" [...] "passeios e viagens registrados por escrito pelas crianças em cadernos, como tarefa escolar, seja como demanda da tradicional redação 'Minhas férias' seja como resultado de atividades pedagógicas, não refletem necessariamente aquilo que se passou ou aquilo que as crianças sentiram ou viveram de fato. Nesse caso, precisa-se tentar evitar uma visão ingênua e simplista das crianças e de suas produções textuais. Sabe-se que na condição de alunos e alunas, como tão bem revelam as narrativas literárias citadas, as crianças encontram estratégias para resolver as tarefas escolares de acordo com os parâmetros da cultura escolar e docente".

Nem sempre se deu visibilidade também às viagens de educadores. No entanto, Antonio Viñao (2000)7, lembra que a "literatura de viagens pedagógicas é um dos gêneros mais conhecidos no âmbito da educação comparada e uma das fontes histórico-educativas mais utilizadas", na medida em que, nela, mesmo os autores pouco falando de si, seus relatos funcionam como "testemunho direto do visto ouvido e vivido" (op.cit. p. 88). Mas, tal como os diários e correspondências de viagem, os livros de viagem, têm despertado interesse entre aqueles que têm se voltado para as viagens de educadores buscando compreender o lugar social dos viajantes, as redes de sociabilidade tecidas, as repercussões em práticas educativas.

Viagens pedagógicas, organizado por Ana Chrystina Mignot e José Gondra, em 2007, Viajar é inventar o futuro: narrativas de formação e o ideário educacional brasileiro nos diários e relatório de Anísio Teixeira em viagem à Europa e aos Estados Unidos (1925-1927), de Silmara de Fátima Cardoso e Dislane Zerbinatti Moraes, em 2014' ${ }^{\circ}$ Mulheres em trânsito: intercâmbios, formação docente, circulação de saberes $e$ práticas pedagógicas, organizado por Alexandra Lima da Silva, Evelyn de Almeida Orlando e Maria José Dantas, em 2015 ${ }^{10}$, exemplificam o esforço para dar a conhecer o modo como

7 VINÃO FRAGO, Antonio. Las autobiografias, memorias y diarios como fuente histórico-educativa: tipologias y usos. Rio de Janeiro: Teias, v. 1, n 1, p. 82-97, 2000.

8 MIGNOT, Ana Chrystina e GONDRA, José (orgs). Viagens pedagógicas. São Paulo: Cortez Editora, 2007.

9 CARDOSO, Silmara de Fátima e MORAES, Dislane Zerbinatti. Viajar é inventar o futuro: narrativas de formação e o ideário educacional brasileiro nos diários e relatório de Anísio Teixeira em viagem à Europa e aos Estados Unidos (1925-1927). São Paulo: Paco Editorial, 2014.

10 SILVA, Alexandra Lima da; ORLANDO, Evelyn e DANTAS, Maria José. Mulheres em trânsito: intercâmbios, formação docente, circulação de saberes e práticas pedagógicas. Curitiba: Editora CRV, 2015. 
modelos pedagógicos circularam, entre países, em função dos deslocamentos feitos por educadores que partiram para ver, ouvir, comparar, experimentar e propagar. Enquanto os dois primeiros se voltam para as motivações, destinos, repercussões e desdobramentos das viagens de homens e mulheres que visitaram outros países em busca de inovações educacionais, o último se detêm nas viagens de mulheres, muitas delas educadoras. Este esforço tem outros desdobramentos na produção acadêmica como dissertações e teses de autoras que estão aqui, neste dossiê, mostrando as possibilidades de entender crônicas de viagens, diários e relatórios como exercícios autobiográficos de educadores em meio às travessias.11

Em Desembarco de la escuela nueva en Buenos Aires: heterogéneas naves en puertos heterogéneos, Héctor Rubén Cucuzza, trabalhando com a metáfora das navegações, a partir do entendimento de que foram muitos navios e muitos e diversificados portos onde a Escola Nova chegou, o autor interpreta a construção deste movimento de educação, a partir

11 Ver: MACHADO, Sara Raphaela Amorim. Viagem como missão: intercâmbio pedagógico de Nestor dos Santos Lima. Rio de Janeiro: Universidade do Estado do Rio de Janeiro, Programa de Pós-graduação em Educação (Tese de doutorado), 2017. 230 f.; CARDOSO, Silmara de Fátima. "Viajar é ser autor de muitas histórias": experiências de formação e narrativas educacionais de professores brasileiros em viagem aos Estados Unidos (1929-1935). São Paulo: Universidade de São Paulo, Programa de Pós-Graduação em Educação (Tese de doutorado), 2015., 236 f.; SILVA, Alexandra Lima da. Escritas de viagem, escritas da história: estratégias de legitimação de Rocha Pombo no campo intelectual. Rio de Janeiro: Universidade do Estado do Rio de Janeiro, Programa de Pós-graduação em Educação (tese de doutorado), 2012. 266 f.; PIMENTA, Jussara. As duas margens do Atlântico: um projeto de integração entre dois povos na viagem de Cecilia Meireles a Portugal (1934). Rio de Janeiro: Universidade do Estado do Rio de Janeiro, Programa de Pós-graduação em Educação (Tese de doutorado), 2008. 374 f. além de NASCIMENTO, Anaíse Cristina do. Pela caravana da fraternidade: unificação do movimento espírita nas memórias do educador Leopoldo Machado. Rio de Janeiro: Universidade do Estado do Rio de Janeiro, Programa de Pósgraduação em Educação (Dissertação de mestrado), 2016. 133 f., que não integra este dossiê. das múltiplas viagens empreendidas por educadores o que permitiu diferentes acolhidas e apropriações das ideias de Ovide Decroly na Argentina e na Colômbia. Ana Chrystina Mignot, por sua vez, em Eternizando travessia: memórias de formação em álbum de viagem, também se detém na produção, circulação e apropriação do ideário da Escola Nova, ao eleger a viagem da educadora católica Laura Jacobina Lacombe, em 1925, ao Instituto JeanJacques Rousseau, principal destino de educadores que viam nas propostas de Adolphe Ferrière, Edouard Claparède, Pierre Bovet e Jean Piaget, a possibilidade de se contraporem a práticas tradicionais de ensino. Em Vestígios autobiográficos na escrita de viagem: o "Diário de Bordo" (1934), Jussara Pimenta se volta para a travessia do Atlântico da poeta, jornalista e educadora Cecília Meireles, que publicou as impressões de viagem à Portugal, no jornal A Nação, onde entrelaçou vida profissional e pessoal, o que permitiu à autora compreender "parte do universo de quem escreve, de quem questiona o seu lugar e também o panorama cultural, político e educacional brasileiro do período". Silmara de Fátima Cardoso no artigo Experiências de formação e narrativas educacionais de professores brasileiros em viagem aos Estados Unidos (1929-1935), analisa os fatores que levaram Anísio Teixeira, enquanto Diretor Geral da Instrução Pública do Distrito Federal, bem como a Associação Brasileira de Educação - $A B E$ - a investirem em viagens de professores brasileiros aos Estados Unidos. Em Entre observações e representações: escrita de si nas narrativas de um educador viajante (1923), Sara Raphaela Amorim explora os sentidos da escrita de si nas narrativas de Nestor Lima, um educador viajante, que deixou registrado seu deslocamento ao sul do Brasil, à Argentina e Uruguai, em relatórios de viagem, nos quais a autora interpreta como uma escrita de si, na medida em que traz "relatos, 
impressões e modos de enxergar o mundo, próprios do sujeito eleito para desempenhar a missão". Entre a casa e a escola: sobre percursos e viagens!, artigo de Danielly Samara Besen, Vera Lucia Gaspar da Silva e Emerson Correia da Silva se trabalha registros memorialísticos de professoras e professores que atuaram no ensino primário catarinense de 1950 a 1980, em particular as passagens acerca das idas e vindas para chegarem à escola. No universo de registros encontrados, os autores assinalam que os mesmos revelam "também que o que caracteriza uma viagem não é apenas a distância percorrida, mas as vicissitudes encontradas no percurso".

0 artigo Escritas de si, escritas da liberdade: representações sobre as viagens em autobiografias de escravizados traz as reflexões de Alexandra Lima da Silva sobre a escrita de sujeitos nascidos no cativeiro, nos Estados Unidos, no século XIX, que fizeram "uso da palavra e das viagens, para construir a própria liberdade". Finalmente, em Construção da imagem de si e do outro: cartas de viagem de Jan Hus para Constança (1414), Thiago Borges de Aguiar mergulha em missivas enviadas pelo clérigo Jan Hus, que estando no exílio desde 1412, inicia, no final do ano de 1414 , uma viagem para a ci- dade de Constança, onde se realizaria um Concílio. Para o autor, ao "longo dessa viagem, ele escreveu uma pequena quantidade de cartas nas quais, entre outras coisas, narra os eventos do percurso, defende suas opiniões e posições, analisa as questões de seu contexto histórico e, por meio dessas ações, constrói uma imagem de si e do outro (de diversos outros)."

Os artigos aqui reunidos no dossiê viagem e narrativas (auto)biográficas sugerem modos de viajar, modos de narrar e se constituem em convite a cada leitor ou leitora para que se deixe embarcar em viagens, narrativas, narrativas de viagens que falam de crianças, mulheres, educadores, escravizados e exilados. Realizadas por diferentes sujeitos em tempos e espaços distintos, para destinos diversos, por razões específicas, os estudos lembram sempre que viagens não começam no dia da partida e não se encerram na hora da chegada. Daí a importância de interpretar os viajantes, os contextos, as motivações, as finalidades e as repercussões de cada travessia.

Ana Chrystina Mignot Programa de Pós-graduação em Educação Universidade do Estado do Rio de Janeiro

Outono de 2017 